\title{
Diagnostic efficacy of gel infusion sonography in post-menopausal bleeding
}

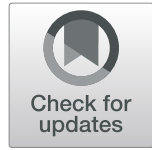

Shimaa Abdalla Ahmed ${ }^{1,2^{*}}$ (D) and Hisham Abo-Taleb ${ }^{3}$ (D)

\begin{abstract}
Background: Our purpose was to evaluate the diagnostic performance of two-dimensional transvaginal ultrasound (2D-TVUS) and gel infusion sonography (GIS) at offline analysis for endometrial characterization compared with realtime evaluation during scanning.

One hundred fifty women presented with PMB. At TVUS, endometrial thickness was $\geq 4 \mathrm{~mm}$ in 122 (81.3\%) women and $<4 \mathrm{~mm}$ in 28 (18.72\%). Among 122 women with endometrial thickness $>4 \mathrm{~mm}$, GIS was successfully performed in 117 (95.9\%). Examinations were stored as video clips for later evaluation (offline analysis) by two less experienced radiologists. Endometrial lesions were classified into four categories: no endometrial abnormality, hyperplasia, polyps, and cancer. Diagnostic efficiency of real-time and offline analysis for diagnosis of each category was calculated and compared, and inter-observer agreement for offline analysis was calculated.

Results: All patients underwent hysteroscopy and/or hysterectomy. Histopathological results confirmed no endometrial abnormality in (27.3\%, 41/150), endometrial hyperplasia in $(12.7 \%, 19 / 150)$, endometrial polyps in $(17.3 \%, 26 / 150)$, and endometrial cancer in $(42.7 \%, 64 / 150)$.

Overall diagnostic accuracy of real-time imaging was $89.7 \%$ (Cl 84-91\%)). The highest accuracy $92.7 \%$ (Cl 88-98\%) was seen in the diagnosis of cancer, and polyps $91.5 \%$ (Cl 86-97\%). The lowest accuracy $75 \%$ (Cl 69-82\%) was seen in hyperplasia.

Overall diagnostic accuracy of offline analysis was $81 \%$, and it increased to $88 \%$ (Cl 83-92\%) after a restricted analysis of good quality clips. The highest accuracy $90.7 \%$ (Cl 83-95\%) was seen in the diagnosis of polyps, and cancer $90.4 \%$ (Cl 83-96\%). The lowest accuracy $71 \%$ (Cl 69-75\%) was seen in hyperplasia.

At offline analysis, the inter-observer agreement was substantial $k=0.77(\mathrm{Cl} 71-84)$ in the evaluation of four endometrial categories after the exclusion of bad quality videos. It was excellent in exclusion of endometrial abnormalities $k=0.85(0.78-0.90)$, substantial in the diagnosis of polyps $k=0.71(0.69-0.88)$, cancer $k=0.61(0.61-$ $0.77)$, and moderate in the diagnosis of hyperplasia $k=0.41(0.30-0.41)$.

Conclusion: Offline 2D analysis with a good image quality has comparable accuracy to a real-time evaluation during scanning in the diagnosis of endometrial lesions. It can increase the accuracy of sonography in ruling out endometrial abnormalities and diagnose non-hyperplastic endometrial pathologies. High NPV and substantial reproducibility can make it an efficient initial screening method in a post-menopausal bleeding.

Keywords: Post-menopause, Uterine bleeding, Endometrial neoplasms
\end{abstract}

\footnotetext{
* Correspondence: shimaaabdalla@aun.edu.eg

${ }^{1}$ South Egypt Cancer Institute, Assiut University, Assiut, Egypt

${ }^{2}$ Assiut, Egypt

Full list of author information is available at the end of the article
}

\section{Springer Open}

(c) The Author(s). 2020 Open Access This article is licensed under a Creative Commons Attribution 4.0 International License, which permits use, sharing, adaptation, distribution and reproduction in any medium or format, as long as you give appropriate credit to the original author(s) and the source, provide a link to the Creative Commons licence, and indicate if changes were made. The images or other third party material in this article are included in the article's Creative Commons licence, unless indicated otherwise in a credit line to the material. If material is not included in the article's Creative Commons licence and your intended use is not permitted by statutory regulation or exceeds the permitted use, you will need to obtain permission directly from the copyright holder. To view a copy of this licence, visit http://creativecommons.org/licenses/by/4.0/. 


\section{Background}

In women with $\mathrm{PMB}$, endometrium should be carefully assessed to obtain correct early diagnosis and proper management [1].

Transvaginal sonography (TVS) with its low cost represents the first-line diagnostic modality in PMB [1], and endometrial thickness $\leq 4$ to $5 \mathrm{~mm}$ can effectively exclude endometrial cancer in a large multicenter study [2] and a meta-analysis [3]. Also, the American College of Obstetrics and Gynecology considers that endometrial sampling is not indicated in this group of patients [4]. Conversely, cancer may be diagnosed with endometrial thickness 4 to $5 \mathrm{~mm}$ [5], and second-line invasive tools (hysteroscopy and endometrial biopsy) may be needed; however, there is no evidence regarding the most optimal second-line diagnostic technique in this issue [6].

Although the endometrial sample is considered the simplest second-line technique in diffuse endometrial abnormalities [1], the rate of endometrial sampling failure ranged from 0 to $58 \%$ in a previous meta-analysis [7]. Endometrial biopsy is less efficient in the diagnosis of focal endometrial lesions like focal hyperplasia, polyps, and polypoid cancers. Thus, sonohysterography could accurately diagnose such lesions and provide a useful guide for hysteroscopy [8].

Saline infusion sonography (SIS) and GIS are currently used in endometrial evaluation [9-13]. GIS was equally effective and even may be advantageous over SIS [8, 11-13]. GIS allows stable filling of the endometrial cavity with a lower failure rate (due to the higher viscosity of gel which allows less backflow through the cervix and a better filling of the endometrial cavity). Also, less volume of the gel was needed to reach a sufficient expansion of the uterine cavity. GIS improved patient comfort with no need for balloon catheterization $[8,13]$.

In PMB, early detection of endometrial cancer at TVUS, infusion sonography may short the time from diagnosis to treatment. With experienced hands, endometrial evaluation by TVUS and infusion sonography yield promising results for the identification of endometrial cancer [14-16]. Ideally, experienced assessors should perform the first-line investigations to ensure accurate diagnosis, but they are rarely available to perform such investigations.

The assessment of TVUS is usually performed in realtime. High skill in image optimization and pathology recognition is usually required. Image optimization was simplified by the modern ultrasound machines and software, but pathology recognition continues to require an expert. Offline analysis of 2D clips by an expert could be an efficient alternative to compensate for the lack of local experts. We conducted this study in our setting to compare real-time evaluation and offline $2 \mathrm{D}$ analysis for endometrial evaluation in PMB.

\section{Methods}

An ethics committee of Assiut university hospital approved this study; 150 women with postmenopausal bleeding were referred from the Gynecology Clinic to the Radiology Department from January 2015 to December 2017. Cases with previous genital tract tumors or those who received hormonal therapy or tamoxifen were excluded. A radiologist with 10 years of experience in gynecologic imaging-performed transvaginal ultrasound (TVUS) examination and patients with endometrial thickness $>4 \mathrm{~mm}$, or immeasurable endometrium will be eligible to 2D GIS (this cutoff level of $4 \mathrm{~mm}$ was recommended by the European Menopause and Andropause Society [17], real-time evaluation results were reported at the end of each examination, and then, systematic videos were stored to be analyzed offline by another two less experienced radiologists ( 3 years of experience in gynecologic imaging).

\section{Real-time imaging (TVUS and GIS)}

All examinations were performed according to a predetermined scanning protocol using LOGIQ 8s X declare, GE (General electric medial system) with endovaginal curved 5-9 $\mathrm{MHz}$ transducer.

Endometrial structure and thickness were evaluated using standard IETA criteria [18]. The following elements were evaluated: internal endometrial echo structure [hypoechoic, hyperechoic, isoechoic, or cystic (regular/irregular)], homogenous, or heterogeneous and endomyometrial junction (sub-endometrial halo): visualization and interruption of endomyometrial junction (regular/irregular, homogenous/heterogeneous).

\section{Gel infusion sonography (GIS)}

GIS was done as previously described [19]. After cleaning of the cervix with povidone-iodine, a sterile neonatal suction catheter with a diameter of about $2.0 \mathrm{~mm}$ was introduced into the cervix for about $2-7 \mathrm{~cm}$ beyond the external os, then speculum was removed, and the catheter held in place, then Instillagel (Farco-Pharma Gmbh, Germany) was instilled. The vaginal probe was reinserted. The pressure was adjusted manually during gel installation until the entire uterine cavity became expanded and visible. The uterine cavity was evaluated using the same parameters on TVUS. Also, endometrial thickness was measured in the sagittal plane (as the sum of the maximum endometrial thickness at the anterior and the posterior walls).

For each case, the mean procedure time and the time during which the cavity remains distended were recorded. The visual analog scale (VAS) was used to measure the degree of pain ( 0 equivalent to no pain and 3 equivalent to severe pain). 
A GIS analysis was done using a standardized coding sheet for GIS parameters defined by the IETA system [18]. The following elements were evaluated: endometrial surface (smooth, polypoid, irregular), the size of the lesion (less than or more than $25 \%$ of the surface), and the surface of the localized lesion (regular or irregular).

At GIS, the diagnosis of cancer was considered in the presence of TVUS signs of cancer and/or irregular surface of a diffuse or focal lesion at GIS \pm disruption to the endometrial-myometrial interface.

Diagnosis of polyps was considered if there were an echogenic, smooth, intracavitary masses arising from endometrium without endo-myometrial interface disruption, and noted polyp limited mobility during an injection can differentiate them from blood clots which are freely movable anywhere in the cavity; also, differentiation from submucosal fibroid can be done by its solid structure of mixed echogenicity emerging from myometrium after disrupting myometrium and bulging into the cavity with acoustic shadowing. The presence of the echogenic endometrial covering layer discriminates it from polyps which arise from the endometrium itself.

Endometrial hyperplasia was diagnosed in the presence of diffuse homogenous endometrial thickening $>4 \mathrm{~mm}$ with an intact endometrial-myometrial interface.

Finally, endometrial findings were classified as (polyp, hyperplasia, cancer, and no endometrial abnormality).

\section{Offline analysis}

During the real-time investigation (TVUS, GIS), 2D clips were obtained for each examination including 1 sweep in an axial plane and 2 in the sagittal plane. The duration of each clip ranges from 5 to $10 \mathrm{~s}$. Three $2 \mathrm{D}$ clips for each examination were stored for their visualization quality and analysis in a separate file (using the patients' ID number). Then, all examinations were given a new ID. All clips were evaluated independently by two less experienced radiologists who were blinded to the patient's identity using a personal computer with virtual organ computer-aided analysis software (GE Healthcare Ultrasound).

Offline analysis of the stored clips was performed on a standard form regarding the image quality and the same morphological endometrial parameters as those obtained at the real-time evaluation. Likert scale was used to score clips' quality from 1 to 5,5 representing a perfect quality and 1 representing a poor quality, and clips' quality depended on image sharpness, brightness, the presence of air bubbles or other artifacts, adequate distension, and visualization of endometrial abnormality. Each of these categories was weighted and could render a point, and poor quality videos were considered if scored less than 3.

\section{Reference standard}

All women underwent hysteroscopy and/or hysterectomy, and histopathology was the reference standard. These procedures were performed within 3-4 weeks of duration after GIS. At hysteroscopy, removal of all focal lesions was attempted and resectoscopic biopsies were taken from the area of diffuse changes. In patients with normal hysteroscopy, a biopsy was taken from the anterior and posterior walls of the uterine cavity. Then curettage was performed. All specimens were evaluated by pathologists specialized in gynecological oncology.

\section{Statistical analysis}

IBM SPSS Statistics version 21 (IBM Corp., Armonk, $\mathrm{NY}$ ) was used for data analysis. $p$ value $<0.05$ was considered statistically significant. Normally distributed data and continuous data are expressed as mean $\pm \mathrm{SD}$. The scored quality of the examinations was compared using McNemar's test. Sensitivity, specificity, positive, negative predictive values, and accuracy of real-time imaging and offline video clip analysis were calculated. ROC curve analysis was used to compare the diagnostic performance of these analyses in the diagnosis of endometrial lesions.

Inter-observer agreement was tested for offline analysis regarding four endometrial categories: no endometrial abnormality, hyperplasia, cancer, and polyp (detection of at least one focal lesion used as respective endpoints). The kappa value of $0.81-1.00$ indicates excellent agreement, a $k$ value of $0.61-0.80$ indicates good agreement, a $k$ value of $0.41-0.60$ indicates moderate agreement, a $k$ value of $0.21-0.40$ indicates fair agreement, and a $k$ value of $<0.20$ indicates poor agreement. The agreement percentage was calculated to compensate for kappa disadvantage as it is influenced by prevalence.

Results One hundred fifty women presented with PMB, and the mean age was $61 \pm 9.3$ years. BMI was $28.2 \pm 4.1$, and parity was $2.7 \pm 1.2$. Histopathological results confirmed no endometrial abnormality in $27.3 \%$ (41/150), endometrial hyperplasia in $12.7 \%$ (19/150), endometrial polyps in $17.3 \%(26 / 150)$, endometrial cancer in $42.7 \%$ $(64 / 150)$, and concomitant submucosal fibroid in $3.3 \%$ (6/150).

At TVUS, endometrial thickness was $\geq 4 \mathrm{~mm}$ in 122 (81.3\%) women and $<4 \mathrm{~mm}$ in $28(18.72 \%)$. The mean endometrial thickness was $19.5 \mathrm{~mm} \pm 4.6 \mathrm{~mm}$. We found that benign endometrial lesions had significantly lower endometrial thickness compared with malignant ones. The mean endometrial thickness in endometrial polyp was $(10 \mathrm{~mm}+2.1 \mathrm{~mm})$, in endometrial hyperplasia (13 $\mathrm{mm} \pm 2.7 \mathrm{~mm})$, while in endometrial cancer $(21 \mathrm{~mm} \pm 2.3 \mathrm{~mm})(p=0.01)$. 
GIS has successfully performed in 95.9\% (117/122) of women who showed thickened endometrium $>4 \mathrm{~mm}$ by TVUS. The mean procedure time was $11.2 \pm 2.1 \mathrm{~min}$, and the meantime of persistence uterine distention was $20.4 \pm 3.7 \mathrm{~min}$. Pain scoring showed no pain (34.2\%), mild pain $(47 \%)$, moderate pain $(8.5 \%)$, and severe pain $(10.3 \%)$. GIS was attempted in $5(4.1 \%)$ women with endometrial thickness $>4 \mathrm{~mm}$, and they underwent hysteroscopic biopsy. The reasons for GIS failure were cervical stenosis $(n=2)$, attenuation from myomas $(n=2)$, and extreme obesity $(n=1)$.

Among 28 women with endometrial thickness $<4 \mathrm{~mm}$, no endometrial cancer was detected after the hysteroscopic biopsy. We found that cutoff endometrial thickness $\geq 4 \mathrm{~mm}$ had $94.7 \%$ sensitivity and $91.2 \%$ specificity in the diagnosis of endometrial cancer. Among 5 women with endometrial thickness $>4 \mathrm{~mm}$ and failed GIS, a hysteroscopic biopsy confirmed cancer in two cases.

Overall sensitivity, specificity, positive predictive value, negative predictive value, and accuracy of realtime imaging in diagnosing endometrial lesions were 92.7\% (CI 89-94\%), 87.2\% (CI 80-88\%), 86.3\% (CI 79-87\%), 93.2\% (CI 89-95\%), and 89.7\% (CI 84-91\%), respectively. The AUC was 0.89 (CI 85-90). The highest accuracy $92.7 \%$ (CI 88-98\%) was seen in the diagnosis of cancer, and polyps 91.5\% (CI 86-97\%). The lowest accuracy 75\% (CI 69-82\%) was seen in hyperplasia (Table 1).

During offline analysis, the poor quality videos were seen in $8.5 \%(10 / 117)$ of examination (it was caused by a lack of distension in 3 cases, poor sharpness in 5 cases, and air bubbles in 2 cases). After the exclusion of poor quality videos from the analysis, overall sensitivity, specificity, positive predictive value, negative predictive value, and accuracy of offline analysis were 90.8\% (CI 89-95\%), 85.6\% (CI 79-88\%), 84.6\% (CI 77-85\%), 91.5\% (CI 86$94 \%$ ), and $88 \%$ (CI 83-92\%), respectively. The AUC was 0.88 (CI 83-92). The highest accuracy 90.7\% (CI 8395\%) was seen in the diagnosis of polyps, and cancer 90.4\% (CI 83-96\%). The lowest accuracy 71\% (CI 69$75 \%$ ) was seen in hyperplasia (Table 2).

At offline analysis, inter-observer agreement regarding four endometrial categories increased from moderate $k=0.59(0.55-0.59)$ to substantial $k=0.77$ (CI 71-84) after the exclusion of poor quality videos. It was excellent in exclusion of endometrial abnormalities $k=0.85$ $(0.78-0.90)$, moderate in the diagnosis of hyperplasia $k=$ 0.41 (0.30-0.41) (Fig. 1), and substantial in the diagnosis of both polyps $k=0.71$ (0.69-0.88) (Fig. 2), and cancer $k=0.61$ (0.61-0.77) (Fig. 3) (Table 3).

\section{Discussion}

The offline analysis had a comparable accuracy to realtime evaluation after the exclusion of bad quality clips. Offline analysis with less experienced radiologist showed high overall sensitivity 90.8\% (CI 89-95\%) and high NPV 91.5\% (CI 86-94\%) which suggest that it may be used as an efficient method in the screening of postmenopausal bleeding to postpone invasive maneuvers. The problem with offline analysis seemed to be a bad image quality; a higher accuracy was obtained when restricted to high-quality images. Thus, image optimization is essential to obtain high-quality images for later offline analysis.

One of the major results in our study, the offline analysis had high NPV 92.6\% (CI 86-94\%) for cancer diagnosis, however, still lower compared to real-time evaluation 95.8\% (CI 83-99), similarly [20]. At offline analysis, three cases were falsely diagnosed as endometrial hyperplasia due to GIS appearance as regular diffusely thickened endometrium. One of these cases was correctly diagnosed at real-time evaluation by detection of small focal interruption of the endometrial myometrial junction. We think offline analysis can be used to provide a useful initial screening in post-menopausal bleeding, and a negative study may lead to postponement of biopsy.

In our study, the PPV of real-time evaluation and offline analysis in diagnosing endometrial cancer was $86 \%$ (CI $82-93 \%$ ) and $87.1 \%$ (CI $80-88 \%$ ), respectively. Five cases with simple endometrial hyperplasia were falsely diagnosed as cancer due to GIS appearance as diffusely thickened endometrium with a slightly irregular surface. Dueholm et al. [1] reported that in PMB women with endometrial thickness $>4 \mathrm{~mm}$, AUC of TVUS + GIS for the prediction of malignancy was $91 \%$, similar to ours. The accuracy of TVUS (endometrial thickness

Table 1 Accuracy of real-time imaging in the diagnosis of four endometrial categories (polyp, hyperplasia, cancer, and no endometrial abnormality) compared to pathology

\begin{tabular}{llllll}
\hline Real-time imaging & Sensitivity \% & Specificity \% & PPV \% & NPV \% & Accuracy \% \\
\hline Polyp & $92(88-97)$ & $91.3(86-93)$ & $90(88-91)$ & $97.7(88-99)$ & $91.5(86-97)$ \\
Hyperplasia & $77(71-79)$ & $65.9(60-67)$ & $68(58-68)$ & $79(78-87)$ & $75(69-82)$ \\
Cancer & $91.4(89-93)$ & $93(88-97)$ & $86(82-93)$ & $95.8(83-99)$ & $92.7(88-98)$ \\
No endometrial abnormality & & & & $90.3(89-93)$
\end{tabular}

Note: sensitivity, specificity, positive predictive value (PPV), negative predictive value (NPV), and accuracy data are percentages. All numbers in parentheses are 95\% Cls 
Table 2 Accuracy of offline analysis in the diagnosis of four endometrial categories (polyp, hyperplasia, cancer, and normal endometrium)

\begin{tabular}{llllll}
\hline Offline analysis & Sensitivity \% & Specificity \% & PPV \% & NPV \% & Accuracy \% \\
\hline Polyp & $91.3(85-93)$ & $92.4(89-96)$ & $89.8(81-90)$ & $95.1(89-97)$ & $90.7(83-95)$ \\
Hyperplasia & $75(69-75)$ & $64.1(58-66)$ & $69.2(68-78)$ & $77.3(70-81)$ & $71(69-75)$ \\
Cancer & $88.2(87-91)$ & $91.4(84-92)$ & $87.1(80-88)$ & $92.6(86-94)$ & $90.4(83-96)$ \\
No endometrial abnormality & & & & $91.2(87-95)$ & \\
\hline
\end{tabular}

Note: sensitivity, specificity, positive predictive value (PPV), negative predictive value (NPV), and accuracy data are percentages. All numbers in parentheses are $95 \% \mathrm{Cls}$

-These results include the analysis of clips after the exclusion of poor quality videos

measurements) in endometrial cancer prediction increased from 87 to $96 \%$ after adding GIS [21]. Opolskiene, et al. [22] reported that the appearance of an endometrial focal lesion with an irregular surface at 2D SIS had 97\% specificity in cancer diagnosis, while diffuse endometrial thickening was not predictive of diagnosis [23] and may carry the possibility of various diagnoses including endometrial hyperplasia, metaplasia, and cancer. So, a biopsy is indicated in diffuse endometrial thickening to detect cellular atypia because endometrial carcinoma may develop in $<2 \%$ of endometrial hyperplasia without atypia and in $23 \%$ of atypical endometrial hyperplasia. We believe that GIS is a worthwhile step between TVUS and hysteroscopy, and even with a less experienced radiologist, it can detect up to $88 \%$ of cancer patients. Also, it can at least guide focal abnormality or suspicious endometrial thickening.

Interestingly, the accuracy of real-time evaluation and offline analysis in the diagnosis of the polyp was $91.5 \%$ (CI 86-97\%) and 90.7\% (CI 83-95\%), respectively, which are close to recently reported by randomized controlled trial [24]. Two cases were falsely diagnosed as having polyps at offline analysis; one of them was correctly classified as negative by real-time evaluation. The explanatory reasons were as follows: In polyps confirmed by hysteroscopy, it depends on the hysteroscopic technique

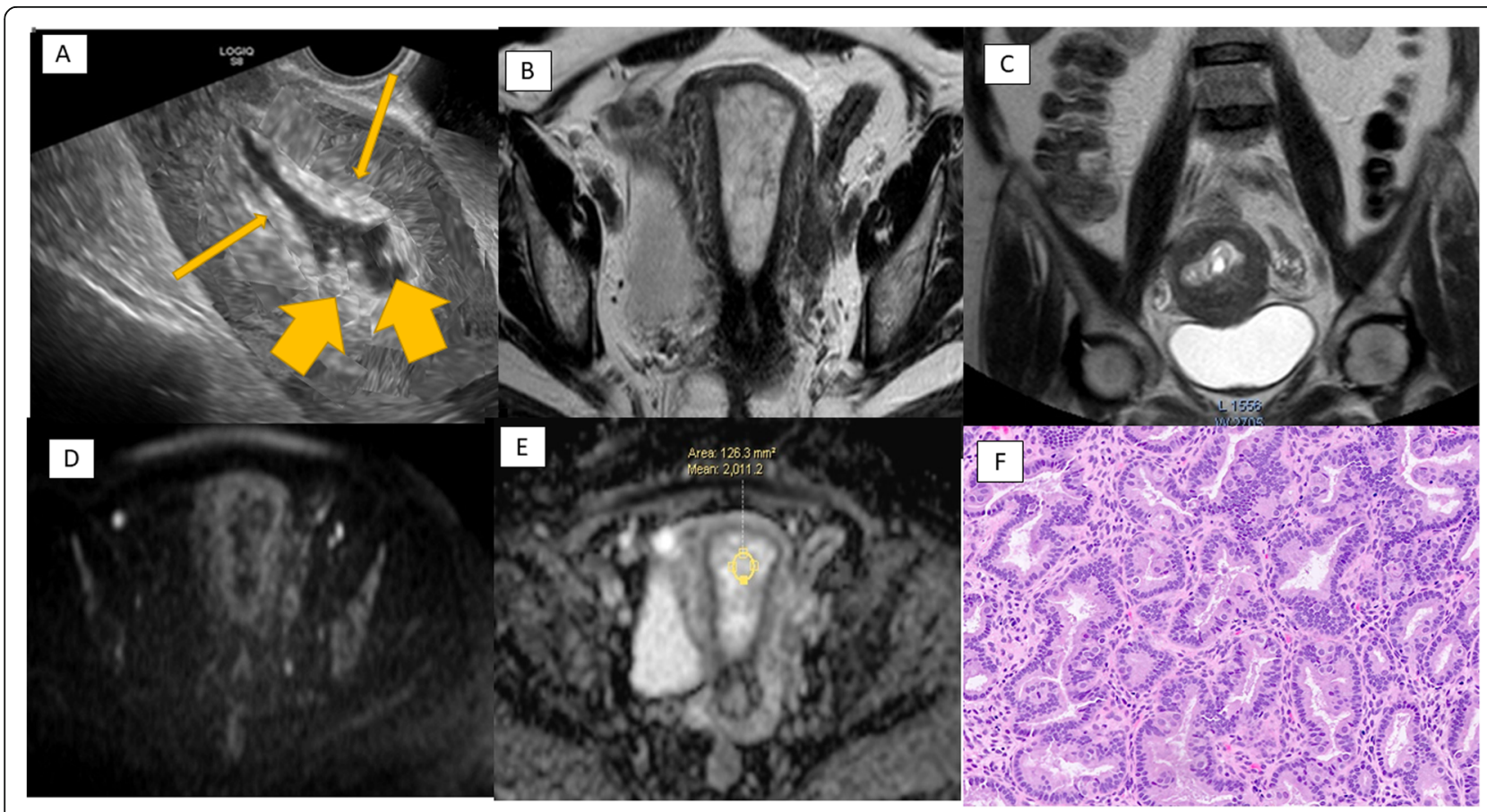

Fig. 1 Post-menopausal female aged 60 years old, presented with PMB. Sonohysterography image (a) showed diffuse thickened endometrium at the lateral uterine walls (long arrows) and focal thickening at the fundus (short arrows) which was considered suspicious for malignancy by both observers. Axial T2WI (b) and coronal T2 WI (c) showed diffusely thickened endometrium of hyper-intense signal and cystic areas, no infiltration of the junctional zone. DWI at $\mathbf{b} 1000 \mathrm{~s} / \mathrm{mm}^{2}$ (d) showed low signal intensity. ADC map (e) ADC value measures about $\pm 2.01 \times 10^{-3} \mathrm{~mm}^{2} / \mathrm{s}$. Microscopic image (f) confirmed endometrial hyperplasia without atypia 


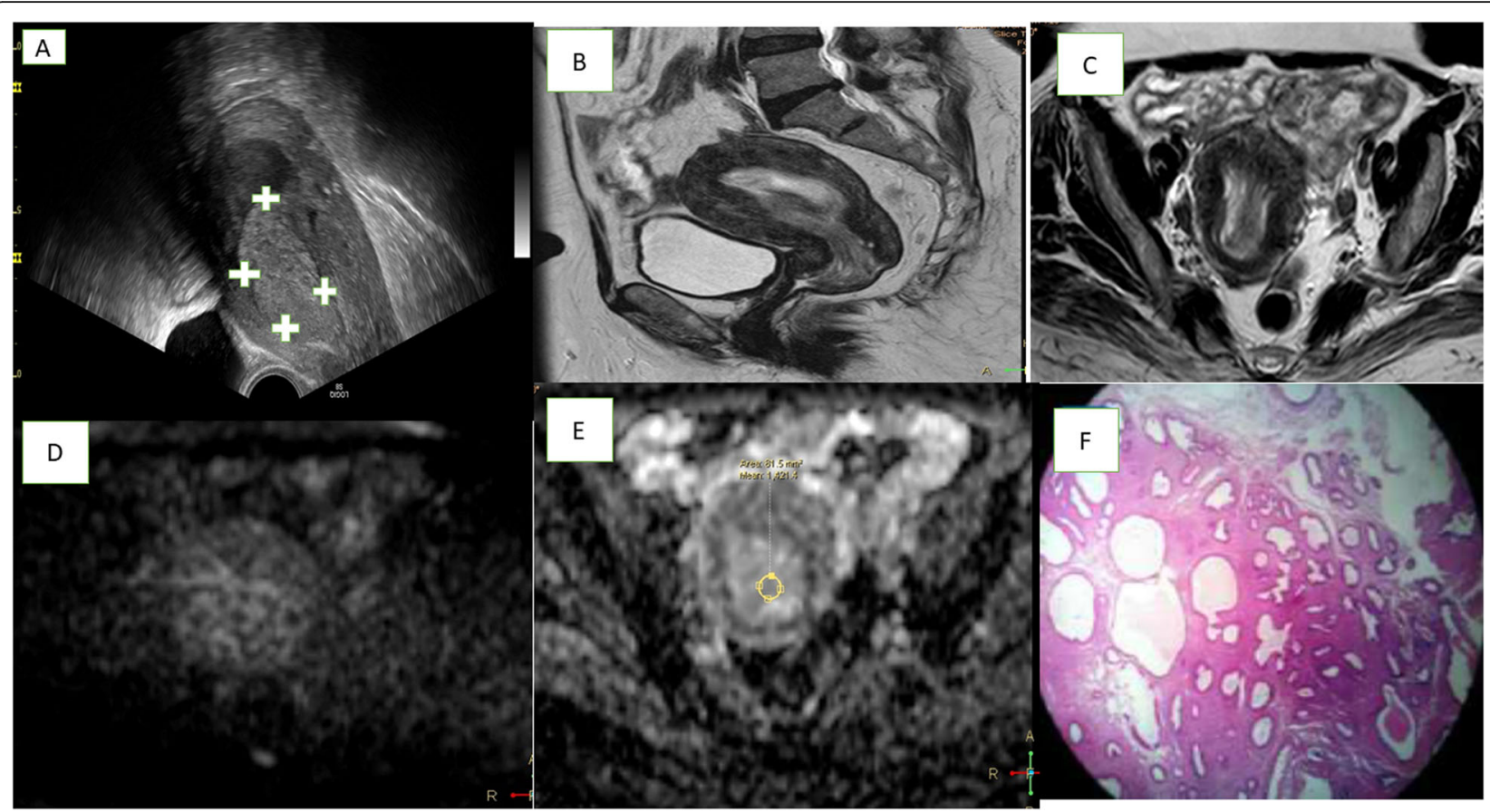

Fig. 2 Post-menopausal female aged 52 years old, presented with PMB. Sonohysterography image (a) showed a well-defined polypoidal hypoechoic soft tissue mass lesion with a smooth surface, and it was diagnosed as endometrial polyp by both observers. Sagittal T2 WI (b), coronal T2 WI (c), and axial T2WI (d) showed an endometrial polypoidal lesion of hypo-intense signal projecting from the uterine body into the cervical canal, no infiltration of the junctional zone or cervical canal. DWI at b $1000 \mathrm{~s} / \mathrm{mm}^{2}$ (e) showed low signal intensity. ADC map (f) ADC value measures about $\pm 1.421 \times 10^{-3} \mathrm{~mm}^{2} / \mathrm{s}(\mathbf{g})$. Microscopic image (h) confirmed endometrial hyperplastic polyp without atypia

used (wide field of view may be obtained by hysteroscopy but advancement beyond a mobile polyp may limit polyp visualization). Also, the polyp may be spontaneously expelled during the time interval between sonohysterography and hysteroscopy. In polyps confirmed by endometrial sampling, a small polyp may be missed by endometrial biopsy. In women with PMB, GIS could triage the need for a subsequent hysteroscopic polypectomy.

Our analysis indicated low accuracy of both real-time and offline analysis in the diagnosis of endometrial hyperplasia. The previous metanalysis of Farquhar et al. [25] reported a wide range of sensitivities and specificities in 4/19 studies concerned with the accuracy of sonohysterography in the detection of endometrial hyperplasia compared to pathology.

Nonspecific ultrasound appearance has been described for endometrial hyperplasia in PMB [26]. Moreover, GIS is not reliable in endometrial hyperplasia diagnosis [27]. It represents a real problem in clinical practice and even experienced hysteroscopists may found difficulty in differentiation between hyperplasia and other endometrial abnormalities [28, 29]. We think detection of cancerous focus is more important than a diagnosis of hyperplasia itself, and adding DWI sequence to routine conventional
MRI may help to detect occult carcinoma within endometrial hyperplasia [30].

Reproducibility of infusion sonography has been previously reported [16, 17, 31-34]; however, their results were in some cases not directly comparable with ours due to differences in outcome parameters or study population.

Interestingly, the offline analysis had good reproducibility in endometrial characterization; similar findings had been reported at GIS [31]; however, the level of agreement decreased with inexperienced observers [32, 33]. However, GIS interpretation is critically dependent on observer experience, and we think observer accuracy is influenced by an adequate level of training rather than years of experience.

It is cheaper and much simpler to evaluate US images remotely than to send the patient to a radiology clinic. This approach is already used for MRI and US for timeconsuming and cost-efficiency. Simply, patients can be classified into four categories based on offline analysis: (1) examinations with thin endometrium, in which endometrial cancer is unlikely; (2) examinations in which benign pathology is likely; (3) examinations in which cancer is very likely and further evaluation is mandatory; and (4) examinations in which additional imaging is indicated. 


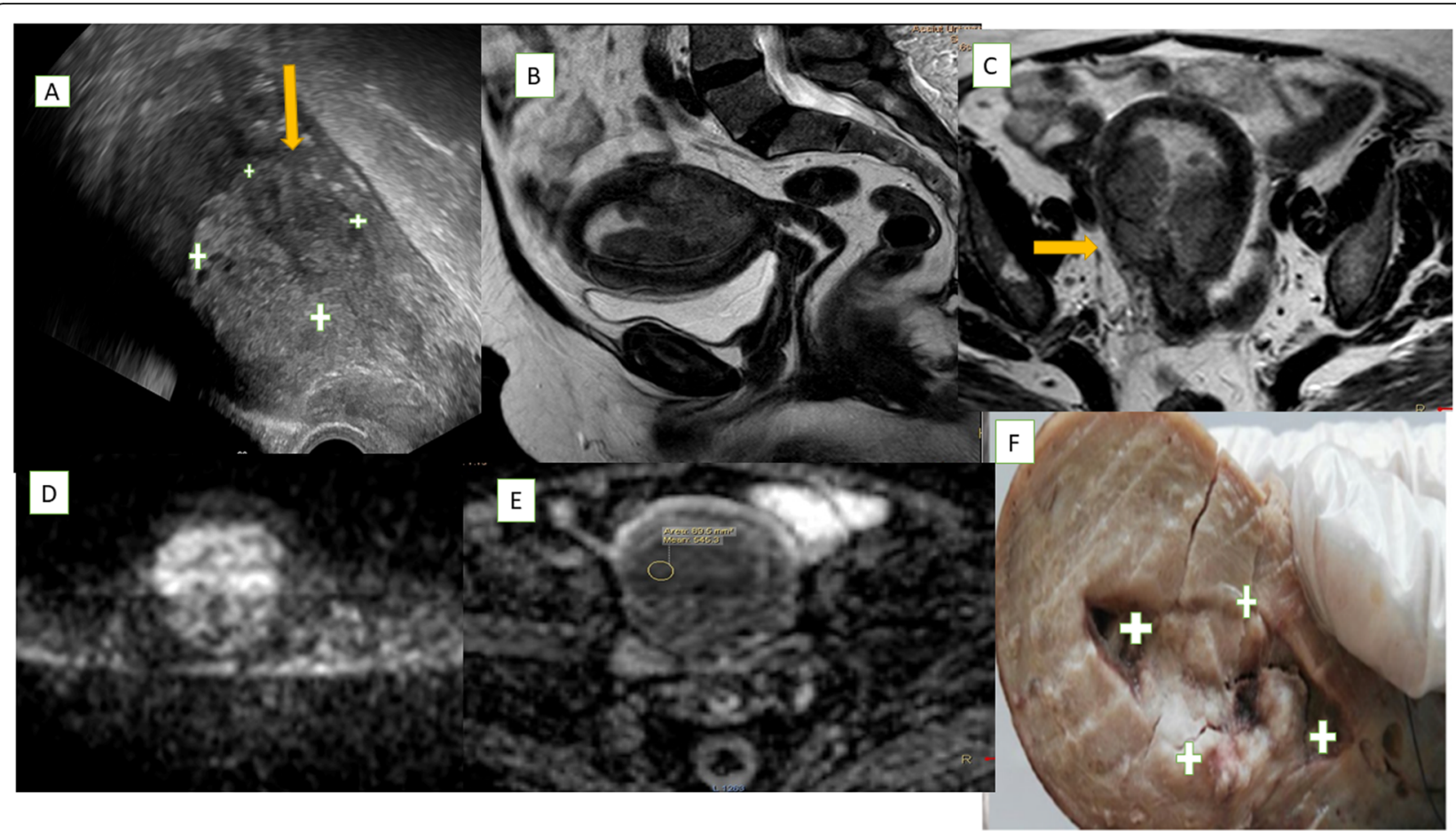

Fig. 3 Post-menopausal female aged 66 years old, presented with PMB. Sonohysterography image (a) showed an irregular endometrial focal mass lesion with disruption of the endometrial myometrial interface (arrow) which was considered suspicious of malignancy be both observers. Sagittal T2WI (b) and axial T2 WI (c) showed an irregular sessile lesion occupying most of the endometrial cavity extending into the internal cervical OS and infiltrating the junctional zone in the right lateral uterine wall with thinned out myometrium and myometrial infiltration more than 50\% (arrow), no parametrial infiltration. DWI at b $1000 \mathrm{~s} / \mathrm{mm}^{2}$ (d) lesion showed high signal intensity. ADC map (e) ADC value measures about $\pm 0.545 \times 10^{-3} \mathrm{~mm}^{2} / \mathrm{s}$. Hysterectomy specimen (f). Operative and histopathological diagnosis was stage IB endometrioid adenocarcinoma

Our limitation includes video clip quality was a problem as it was acquired as sweep and may contribute to the discrepancies, and also, clips obtained by an expert observer may increase observer reproducibility because, in ultrasound, visualization skill was the most important factor in diagnosis. In unselected women with PMB and the main issue was to discriminate between normal and abnormal endometrium, better GIS interobserver agreement results might be expected. For the sake of simplifying the test, we did not use 3D reconstruction; so we recommend future studies including previously mentioned technology. Based on these GIS results, we will develop a predictive model for the diagnosis of endometrial cancer.

\section{Conclusion}

Offline 2D analysis with a good image quality has comparable accuracy to real-time evaluation during scanning in the diagnosis of endometrial lesions. It can increase the accuracy of sonography in ruling out endometrial abnormalities and diagnose non-hyperplastic endometrial pathologies. High NPV and substantial reproducibility can make it an efficient initial cancer screening method in post-menopausal bleeding.

Table 3 Cohen's kappa coefficient for inter-observer agreement at offline analysis

\begin{tabular}{lll}
\hline Endometrial category & $\boldsymbol{k}^{*}(\mathbf{9 5} \%$ confidence interval) & Agreement percentage \\
\hline Abnormality (yes/no) & $0.85(0.78-0.90)$ & 91 \\
polyp (yes/no) & $0.71(0.69-0.88)$ & 89 \\
Hyperplasia (yes/no) & $0.41(0.30-0.41)$ & 65 \\
Cancer (yes/no) & $0.61(0.61-0.77)$ & 89 \\
Total all four categories & $0.59(0.55-0.59)$ & 82 \\
Total all four categories with clips of high quality only & $0.77(71-84)$ & 88 \\
\hline
\end{tabular}




\section{Abbreviations}

GIS: Gel infusion sonohysterography; TVUS: Transvaginal ultrasound; PMB: Post-menopausal bleeding; SIS: Saline infusion sonography; 2D: Two dimensional; D\&C: Dilatation and curettage

\section{Acknowledgements}

Not applicable

\section{Authors' contributions}

Both authors (SA and $\mathrm{HA}$ ) contributed equally to the data analysis, methodology, and study design. SA was a major contributor in writing the manuscript. Both authors approved the final manuscript.

\section{Funding}

No disclosure of funding received for this work.

\section{Availability of data and materials}

The datasets used and/or analyzed during the current study are available from the corresponding author on reasonable request.

\section{Ethics approval and consent to participate}

This study was approved by the Assiut Medical Ethical Review Board (NO. 17100340). Written informed consent was obtained from all women participating in the study.

\section{Consent for publication}

All patients included in this research gave written informed consent to publish the data contained within this study. If the patient was less than 16 years old, deceased, or unconscious when consent for publication was requested, written informed consent for the publication of this data was given by their parent or legal guardian.

\section{Competing interests}

The authors declare that they have no competing interests.

\section{Author details}

${ }^{1}$ South Egypt Cancer Institute, Assiut University, Assiut, Egypt. ${ }^{2}$ Assiut, Egypt.

${ }^{3}$ Women Health Hospital, Assiut University, Assiut, Egypt.

Received: 14 May 2020 Accepted: 7 September 2020

Published online: 23 September 2020

\section{References}

1. Dueholm M, Marie I, Hjorth D, Dahl K (2015) Estrid Stær Hansen, and Gitte rtoft. Ultrasound scoring of endometrial pattern for fast-track identification or exclusion of endometrial cancer in women with postmenopausal bleeding. Journal of Minimally Invasive Gynecology. J Minim Invasive Gynecol 22:1036-1044

2. Karlsson B, Granberg S, Wikland M et al (1995) Transvaginal ultrasonography of the endometrium in women with postmenopausal bleeding Nordic multicenter study. Am J Obstet Gynecol 172:1488-1494

3. Smith-Bindman R, Kerlikowske K, Feldstein VA et al (1998) Endovaginal ultrasound to exclude endometrial cancer and other endometrial abnormalities. JAMA. 280:1510-1517

4. American College of Obstetricians and Gynecologists (2009) ACOG committee opinion no. 426: the role of transvaginal ultrasonography in the evaluation of postmenopausal bleeding. Obstet Gynecol 113:462-464

5. Timmermans A, Opmeer BC, Khan KS et al (2010) Endometrial thickness measurement for detecting endometrial cancer in women with postmenopausal bleeding: a systematic review and meta-analysis. Obstet Gynecol 116:160-167

6. van HN, Breijer MC, Khan KS et al (2011) Diagnostic evaluation of the endometrium in postmenopausal bleeding: an evidence-based approach. Maturitas. 68:155-164

7. Dijkhuizen FP, Mol BW, Brolmann HA, Heintz AP (2000) The accuracy of endometrial sampling in the diagnosis of patients with endometrial carcinoma and hyperplasia: a meta-analysis. Cancer. 89:1765-1772

8. Werbrouck E, Veldman J, Luts J, Van Huffel S, Van Schoubroeck D, Timmerman D, Van den Bosch T (2011) Detection of endometrial pathology using saline infusion sonography versus gel instillation sonography: a prospective cohort study. Fertil Steril 95(1):285-288
9. Van Den Bosch T, Van Schoubroeck D, Luts J, Bignardi T, Condous G, Epstein E, Leone FP, Testa AC, Valentin L, Vanhuffel S, Bourne T, Timmerman D (2011) Effect of gel-instillation sonography on Doppler ultrasound findings in endometrial polyps. Ultrasound Obstet Gynecol 38(3):355-359

10. El-Faissal Y, El lithy A (2015) Gel-instillation versus saline infusion during sonohysterography: any advantages? Middle East Fertil Soc J 20:6-10

11. Erdem M, Bilgin U, Bozkurt N, Erdem A (2007) Comparison of transvaginal ultrasound and saline infusion sonohysteroscopy in evaluating the endometrial cavity in pre- and postmenopausal women with abnormal uterine bleeding. Menopause 14:846-852

12. Moschos E, Ashfaq R, Mclntire DD, Liriano B, Twickler DM (2009) Saline infusion sonography endometrial sampling compared with endometrial biopsy in diagnosing endometrial pathology. Obstet Gynecol 113:881-887

13. Van den Bosch $T$, Betsas $G$, Van Schoubroeck D, Daemen A, Vandenbroucke V. Cornelis A, De Moor B, Deprest J, Timmerman D (2009) Gel infusion sonography in the evaluation of the uterine cavity. Ultrasound Obstet Gynecol 34(6):711-714

14. Epstein E, Valentin L (2006) Gray-scale ultrasound morphology in the presence or absence of intrauterine fluid and vascularity as assessed by color Doppler for discrimination between benign and malignant endometrium in women with postmenopausal bleeding. Ultrasound Obstet Gynecol 28:89-95

15. Epstein E, Skoog L, Isberg PE, De Smet F, De Moor B, Olofsson PA, Gudmundsson S, Valentin L (2002) An algorithm including results of grayscale and power Doppler ultrasound examination to predict endometrial malignancy in women with postmenopausal bleeding. Ultrasound Obstet Gynecol 20:370-376

16. Opolskiene G, Sladkevicius P, Valentin L (2007) Ultrasound assessment of endometrial morphology and vascularity to predict endometrial malignancy in women with postmenopausal bleeding and sonographic endometrial thickness $>$ or $=4.5 \mathrm{~mm}$. Ultrasound Obstet Gynecol 30:332-340

17. Dreisler E, Poulsen LG, Antonsen SL et al (2013) EMAS clinical guide: assessment of the endometrium in peri and postmenopausal women. Maturitas. 75:181-190

18. Leone FP, Timmerman D, Bourne T, Valentin L, Epstein E, Goldstein SR, Marret H, Parsons AK, Gull B, Istre O, Sepulveda W, Ferrazzi E, Van den Bosch T (2010) Terms, definitions and measurements to describe the sonographic features of the endometrium and intrauterine lesions: a consensus opinion from the International Endometrial Tumor Analysis (IETA) group. Ultrasound Obstet Gynecol 35:103-112

19. Dueholm M, Holm JW, Rydbjerg S, Hansen ES, Ortoft G (2015) Twodimensional and 3-dimensional transvaginal ultrasound with addition of power Doppler angiography and gel infusion sonography for the diagnosis of endometrial malignancy. Ultrasound Obstet Gynecol 45:734-743

20. Aslam M, ljaz L, Tariq S et al (2007) Comparison of transvaginal sonography and saline contrast sonohysterography in women with abnormal uterine bleeding: correlation with hysteroscopy and histopathology. Int J Health Sci (Qassim) 1(1):17-24

21. Dueholm M, Møller C, Rydbjerg S, Hansen ES, Ørtoft G (2014) An ultrasound algorithm for identification of endometrial cancer. Ultrasound Obstet Gynecol 43:557-568

22. Opolskiene G, Sladkevicius P, Valentin L (2009) Two- and three-dimensional saline contrast sonohysterography: interobserver agreement, agreement with hysteroscopy and diagnosis of endometrial malignancy. Ultrasound Obstet Gynecol 33:574-582

23. Jorizzo Johanna R, Chen Michael YM et al (2002) Spectrum of endometrial hyperplasia and its mimics on saline hysterosonography. AJR 179(385-389): 0361

24. van Hanegem N, Breijer MC, Slockers SA, Zafarmand MH, Geomini PMAJ, Catshoek R et al (2016) Diagnostic workup for postmenopausal bleeding: a randomized controlled trial. Int J Gynaecol Obstet. https://doi.org/10.1111/ 1471-0528.14126

25. Farquhar C, Ekeroma A, Furness S, Arroll B (2003) A systematic review of transvaginal ultrasonography, sonohysterography and hysteroscopy for the investigation of abnormal uterine bleeding in premenopausal women. Acta Obstet Gynecol Scand 82:493-504

26. Valentin $L$ (2014) Imaging techniques in the management of abnormal vaginal bleeding in non-pregnant women before and after menopause. Best Prac Res Clin Obstet Gynaecol 28:637-654

27. Dueholm M, Hjorth IMD, Secher P, Jørgensen A, Ørtoft G (2015) Reproducibility of endometrial pathologic findings obtained on 
hysteroscopy, transvaginal sonography, and gel infusion sonography in women with postmenopausal bleeding. J Minim Invasive Gynecol 22:1036-1044

28. Lasmar RB, Barrozo PR, de Oliveira MA, Coutinho ES, Dias R (2006) Validation of hysteroscopic view in cases of endometrial hyperplasia and cancer in patients with abnormal uterine bleeding. J Minim Invasive Gynecol 13:409-412

29. Garuti G, Cellani F, Garzia D, Colonnelli M, Luerti M (2005) Accuracy of hysteroscopic diagnosis of endometrial hyperplasia: a retrospective study of 323 patients. J Minim Invasive Gynecol 12:247-253

30. Ahmed SA, El Taieb HA, Abotaleb H (2018) Diagnostic performance of sonohysterography and MRI diffusion in benign endometrial lesion characterization. Egypt J Radiol Nucl Med 49:579-589

31. Lotte L. Nieuwenhuis A, Marjolein (A.J.) Bij de Vaate A, Wouter J.K. et al. Diagnostic and clinical value of 3D gel installation sonohysterography in addition to $2 \mathrm{D}$ gel installation sonohysterography in the assessment of intrauterine abnormalities. Eur J Obstet Gynecol Reprod Biol. 175 (2014) 67-74.

32. de Kroon CD, Louwe LA, Trimbos JB, Jansen FW (2004) The clinical value of 3-dimensional saline infusion sonography in addition to 2-dimensional saline infusion sonography in women with abnormal uterine bleeding: work in progress. J Ultrasound Med 23(November (11)):1433-1440

33. Beemsterboer SN, Thurkow AL, Verstraeten R, Brolmann HA (2008) Reproducibility of saline contrast sonohysterography for the detection of intracavitary abnormalities in women with abnormal uterine bleeding. Ultrasound Obstet Gynecol 31(April (4)):445-449

34. Dueholm M, Lundorf E, Sorensen JS et al (2002) Reproducibility of evaluation of the uterus by transvaginal sonography, hysterosonographic examination, hysteroscopy, and magnetic resonance imaging. Hum Reprod 17:195-200

\section{Publisher's Note}

Springer Nature remains neutral with regard to jurisdictional claims in published maps and institutional affiliations.

\section{Submit your manuscript to a SpringerOpen ${ }^{\circ}$ journal and benefit from:}

- Convenient online submission

- Rigorous peer review

- Open access: articles freely available online

High visibility within the field

- Retaining the copyright to your article

Submit your next manuscript at $\boldsymbol{\nabla}$ springeropen.com 